\title{
Impact of Commercial Banks' Lending to Small and Medium Scale Enterprises on Economic Growth of Nepal
}

\author{
Kiran Bahadur Pandey \\ Associate Professor, Tribhuvan University, Patan Multiple Campus, Nepal
}

\begin{abstract}
This paper reflects the allocation of small and medium scale enterprises loan by the commercial bank of Nepal and their subsequent reflection on the GDP growth. The study objectives were to establish how the SME lending of commercial bank is contributing toward the growth of the economy. There is strong and long term relationship between SME lending of commercial bank and economic growth. Banking system credit have no significant effect on economic growth of Nepal. The prevailing rate of interest affected the economy towards the negative growth. This paper is based on the secondary source of information briefly explain the potentiality of SME loan for the GDP growth of Nepal.
\end{abstract}

Key words: GDP, SME loan, commercial bank

\section{INTRODUCTION}

The development of small and medium enterprises (SMEs) and changes in their structure over time contribute toward employment generation, market expansion, and economic growth.These enterprises, often called the foundation enterprises, are the core of industrial base. They are the primary vehicles by which new entrepreneurs provide the economy with a continuous supply of ideas, skills, and innovations. Recent empirical studies show that SMEs contribute to over $55 \%$ of GDP and over $65 \%$ of total employment in high-income countries. In low-income countries, especially in the least developed economies, the contribution of SMEs to employment and GDP is less than that of the informal sector, where the great majority of the poorest of the poor make a subsistence level of living.

The financial sector plays a central role in the growth and development of the economy through mobilization and deployment of financial resources. SME finance is challenging. They largely depend on bank loans and trade credit to raise external finance. The "conventional wisdom" on SME finance argues that "supply- side" factors are at the root of the inadequate financing of SMEs. In particular, the way in which financial institutions operate is biased against offering SME financing.There are a large number of SMEs all over the world undergoing financing constraints, which have been inducing a huge loss of social welfare for a longer time. 
Commercial bank occupies the significant amount of market share in Nepalese finance market because of the high penetration of bank in every corner of Nepal.As of July 2015, commercial banks occupies 78.7\% of Assets/ Liabilities.As such the credit policy followed by these bank play greater role in the credit accessibility of Nepal.If due to lack of credit SMEs cannot expand their business then this will ultimately affect the economic growth of Nepal.

As a result of liberalization, the number of commercial banks has increased to 28 some of which have foreign bank equity participation.In urban areas, banks continue to favor short-term lending and maintain a high spread between deposit and lending rates. Apart from rural development banks, formal banking institutions are confined to urban areas because of high operating costs in rural areas.Many SMEs are reluctant to seek formal sector credit because they consider the process complicated and overly bureaucratic. Instead, they continue to depend on informal credit, despite high interest rates, owing to its easy and timely availability.

On the given background the objective of this paper is to analyse the effect of commercial banks' lending to small and medium scale enterprises on the economic growth of Nepal.

\section{LITERATURE REVIEW}

There are many studies carried to know the impact of financial sector development on the economic growth of nations, both developed and developing. This study makes a quick survey of studies relating to developing countries. Taking the case of Nepal, Khatri, Aryal and Sapkota (2008) investigated the contribution of financial institutions to the economic growth using Deposit/GDP ratio, etc., in a developing country setting in Nepal; and to study the development of the commercial banks in Nepal in recent decades. In this study they had done correlation analysis of financial ratio of the commercial banks. Based on the correlation analysis they had concluded that the ratio of deposit to GDP is found to be significant at $6.5 \%$ level to the growth rate of the GDP per capita. The correlation showed that these two variables are highly correlated with the coefficient equals to 0.49 . It has concluded that the saving rate in a country is crucial to the economic development (GDP per capita), especially for developing country.

Nepal Rastra Bank (2009) analysed the impact of the development of the financial sector on the economic growth of Nepal over the period of 1975-2007. It used financial 
variables like sum of total currency plus demand and interest-bearing liabilities of commercial banks as a ratio of nominal GDP the ratio of total credit of commercial banks to nominal GDP including other control variables such as export, government consumption, and investment and population growth. By estimating different regression equations and granger causality test the study found that development of the financial substantially affected economic growth of Nepal over the period studied.

A study by Aurang (2012) was done on the contribution of the commercial banking sector on economic growth in Pakistan. The aim of the study was to investigate the contributions of the commercial banking sector on Pakistan's economic growth. The study was done on 10 banks for the period of 1981 to 2010. Analysis of the data from the 10 banks was done using the Augmented Dickey Fuller (ADF) (1981), PhilipPerron (1988) unit root test, ordinary least square and the granger causality test. The regression results indicated that deposits, investments, advances, profitability and interest earnings had significant positive impact on economic growth. The GrangerCausality test confirmed that there was a bidirectional causal relationship between deposits, advances and profitability and economic growth. The study concluded that activities in the banking sector, including advances by the commercial banks, affected economic growth.

Zhang, Wang and Wang (2012) investigated and established the relationship between financial development and economic growth in China. The study was done at city level. 286 Chinese cities were studied over the five year period between 2001 and 2006. The study applied both traditional cross-sectional regression and first-differenced and system GMM estimators for dynamic panel data. The results of the research suggested that most traditional indicators of financial development like Credit, Deposit, Savings, the share of fixed asset investment financed by domestic loans relative to that financed by state budgetary appropriation positively related to economic growth. However, the ratio of corporate deposits to total deposits had a negative effect on economic growth. This study showed that credit had positive effect on economic growth.

Uremadu, Ogechi and Okwuchukwu (2014) carried out study to examine the contributions of banking system credit to SMEs and their impact on the growth and development of Nigerian economy. This study investigated the impact of banking system credit to small and medium scale enterprises on economic growth of Nigeria using the ordinary least square (OLS) estimation techniques. Annual data spanning 
from 1981 to 2013 were tested for stationary, and co-integration analyses were carried out. The study revealed that the banking system credit to SMEs though gradually increased from year to year as a result of increase in population and hence economic activities, the credit to SMEs as a percentage of total credit to the private sector declined yearly. Banking system credit to SMEs was not significant and thus did not contribute meaningfully to economic growth in Nigeria though bank credit to SMEs as a percentage of total credit to the private sector had a positive and significant effect on growth.

Ochido (2016) study established how credit accessibility affects growth of SMEs. Data was collected using a structured questionnaire which was administered to 379 entrepreneurs in Nairobi County. The results indicated that majority (65 percent) of the SMEs owners that participated in this study had not received any credit. The findings also imply that businesses operated by individuals with no access to credit were likely to collapse because they were unserved financially. The findings showed that $10 \%$ had received credit only once, $7.1 \%$ had received credit twice and another $8 \%$ had received credit thrice. Only $9.7 \%$ indicated to have received credit more than three times. The findings imply that most of the SMEs that were lack enough to received credit only received it once. The findings further revealed the lack of adequate credit accessibility by SMEs.

\section{RESEARCH METHODOLOGY}

\section{Sampling Frame and Sample size}

In this study 28 commercial bank (A class financial institution as classified by NRB) which are operating within the Nepal are taken into account. The SME loan of these commercial bank is taken for this study in the period between "2000-2015". The 16 years' time series data is taken for the study.The data is available from the NRB publication which shows the SME loan allocated by each financial institution and in each of the study year.The interest on which the SME loans are allocated is available from the publication of NRB. The data on RGDP of an economy is available from the economic survey and central bureau of statistics.

\section{Empirical Approach}

This study is the time series analysis, so we have to go through the stationary test before the correlation analysis. Stationarity was carried out using the Augmented Dickey Fuller (ADF) test statistic and Philip Peron test to investigate the presence or 
otherwise of unit root.The co-integration test helps us to understand the whether the long term relationship exist between the variable.Johansen co-integration test was used to test the existence or otherwise of long run equilibrium relationship among variables. After this process, hypothesis testing is done to for testing the significance of relationship between independent and dependent variable.If the hypothesis is true than the inference made about the characteristics of the population parameter from the sample truly reflect the population characteristics.

\section{Model Specification}

The present study recognized the fact that lending rate, and total bank credit to SMEs influences liquidity and direction of credit in an economy. They therefore have been included as control variables in the model and hence the model is specified as follows:

InRGDPt $=\alpha 0+\mathrm{b} 1 \operatorname{InBCrTSMEst}+\mathrm{b} 2 \operatorname{InRBCrTSMEst}+\mathrm{b} 3 \operatorname{InBLR} \mathrm{t}+\mathrm{e}$

Where:

RGDP $=$ Real gross domestic product BCrTSMEs $=$ Small and medium scale enterprise financing proxied by total bank credit to SMEs; RBCrTSMEs= Banks credit to SMEs as a percentage of total credit to the private sector ; $\mathrm{BLR}=\mathrm{Banks}$ lending rate ; $\mathrm{In}=\log =$ Natural logarithm ; $\alpha 0=$ constant; $\mathrm{b} 1$ to $\mathrm{b} 3=$ coefficients to be estimated; $\mathrm{e}=$ stochastic variable or error term

\section{FINDINGS}

This study investigated the impact of commercial bank credit to small and medium scale enterprises on economic growth of Nepal using the co-integration analysis. The times series data spanning from 2000 to 2015 were tested using various techniques. The Stationarity test was done using the tools such as ADF test and PP test. The result of both ADF and PP test revealed that the data are non-stationary. Therefore, the data were made stationary by the first order difference. After the first order difference, the calculated value of all the variable was below critical value at both $1 \%$ and $5 \%$ level of confidence. 
Table 1: Augmented Dickey Fuller and Philip Perron Unit Root Test Result

\begin{tabular}{|c|c|c|c|c|c|c|c|}
\hline \multirow[b]{2}{*}{ Variables } & \multirow[b]{2}{*}{ Coefficients } & \multicolumn{3}{|c|}{ At level } & \multicolumn{3}{|c|}{ First Difference } \\
\hline & & $\begin{array}{l}\text { Test } \\
\text { statistics }\end{array}$ & $\begin{array}{l}1 \% \text { Critical } \\
\text { value }\end{array}$ & $\begin{array}{l}5 \% \\
\text { Critical } \\
\text { value }\end{array}$ & $\begin{array}{l}\text { Test } \\
\text { statistics }\end{array}$ & $\begin{array}{l}1 \% \text { Critical } \\
\text { value }\end{array}$ & $\begin{array}{l}5 \% \\
\text { Critical } \\
\text { value }\end{array}$ \\
\hline \multirow{3}{*}{ Ln RGDP } & PP-> Z(rho) & -0.909 & -17.200 & -12.500 & -24.410 & -17.200 & -12.500 \\
\hline & $\mathrm{ADF}->\mathrm{Z}(\mathrm{t})$ & -1.002 & -3.750 & -3.000 & $-3.754^{*}$ & -3.750 & -3.00 \\
\hline & $\mathrm{p}$-value $\mathrm{Z}(\mathrm{t})$ & 0.7524 & & & 0.0034 & & \\
\hline \multirow{3}{*}{ Ln BCrTSMEs } & $\mathrm{z}(\mathrm{rho})$ & -16.536 & -17.200 & -12.500 & -20.506 & -17.200 & -12.500 \\
\hline & $\mathrm{ADF}->\mathrm{z}(\mathrm{t})$ & -1.360 & -3.750 & -3.000 & $-6.040^{*}$ & -3.750 & -3.00 \\
\hline & $\mathrm{p}$-value $\mathrm{Z}(\mathrm{t})$ & 0.6012 & & & 0.000 & & \\
\hline \multirow{3}{*}{ LnRBCrTSMEs } & $\mathrm{z}$ (rho) & 0.377 & -17.200 & -12.500 & -21.736 & -17.200 & -12.500 \\
\hline & $\mathrm{ADF}->\mathrm{z}(\mathrm{t})$ & -1.873 & -3.750 & -3.00 & $-5.970^{*}$ & -3.750 & -3.000 \\
\hline & $\mathrm{p}$-value $\mathrm{Z}(\mathrm{t})$ & 0.3450 & & & 0.0000 & & \\
\hline \multirow{3}{*}{ Ln BLR } & $\mathrm{z}$ (rho) & -7.450 & -17.200 & -12.500 & -18.444 & -17.200 & -12.500 \\
\hline & $\mathrm{ADF}->\mathrm{z}(\mathrm{t})$ & -1.581 & -3.750 & -3.000 & $-4.012^{*}$ & -3.750 & -3.000 \\
\hline & $\mathrm{p}$-value $\mathrm{Z}(\mathrm{t})$ & 0.4934 & & & 0.0000 & & \\
\hline
\end{tabular}

In Table 1, z (rho) and $\mathrm{z}(\mathrm{t})$ is tabulated for PP test and $\mathrm{z}(\mathrm{t})$ for ADF test. As shown by the table the data are non-stationery, since the value of test statistics is higher than critical values at $1 \%$ and $5 \%$ i.e. acceptance of null hypothesis, this implies there is unit root and so on. After the first difference, all the data are stationery assuring that the value of test statistics for $\mathrm{z}$ (rho) and $\mathrm{z}(\mathrm{t})$ is significantly lower than the critical values. The variable Ln RGP has the test statistics value of -24.410 which is significantly less than the $1 \%$ critical value of -17.200 i.e. rejection of null hypothesis implies that there is no unit root and similar result for other. LnBCrTSMEs, , Ln RBCrTSMEs, LnBLR have the test value of $-6.040,-12.736,-5970$, and -4.012 respectively which is less than $1 \%$ critical value of -3.750 . The result of the stationary test implies that the series isn't auto correlated. There is no relationship between the data in the series.

After the stationarity test, the co-integration test is carried out. The result of the Johansen (1991) co-integration test given in Table 2 reveal that there were 2 cointegration equation at the $95 \%$ level of confidence. 
Table 2: Johansen Co-integration Test Result

\begin{tabular}{llcccc}
\hline Maximum Rank & Parms & \multicolumn{1}{l}{ LL } & Eigenvalue & Trace Statistics & 5\% critical Value \\
\hline None $^{*}$ & 30 & 29.66 & & 943.39 & 68.52 \\
At most 1* & 39 & 267.41 & 1.00 & 467.90 & 47.21 \\
At most 2* & 46 & 489.83 & 1.00 & $23.06^{*}$ & 29.68 \\
At most 3* & 51 & 496.05 & 0.59 & 10.63 & 15.41 \\
At most 4 & 54 & 500.26 & 0.45 & 2.19 & 3.76 \\
At most 5* & 55 & 501.36 & 0.14 & - & - \\
\hline
\end{tabular}

In Table 2, the co-integration with trace test giving 2 co-integration equation at the 5\% level of significance is denoted by *i.e. maximum rank 2 where null hypothesis that there is no co-integration equation has accepted. The trace statistics at the maximum rank value 2 is 23.0605 which is significantly less than $5 \%$ critical value 29.68 . It indicates that there are 2 co-integrating equation at $95 \%$ confidence level.Finally the impact of selected explanatory variables on the growth obtained by the ordinary least squares (OLS) method is shown in Table 3.

Table 3: Estimated Value of Parameter (OLS Regression Analysis)

\begin{tabular}{lcccc}
\hline $\ln R G D P$ & Coef. & Std. Err. & $\mathrm{t}$ & $\mathrm{P}>|\mathrm{t}|$ \\
\hline $\mathrm{C}$ & 11.50178 & 1.601395 & 7.18 & 0.000 \\
$\ln$ BCrTSMEs & .5762421 & .1096627 & 5.25 & 0.000 \\
$\ln$ RBCrTSMEs & -.6172398 & .1111052 & -5.56 & 0.000 \\
$\ln$ BLR & -.3135256 & .4589548 & -0.68 & 0.509 \\
\hline
\end{tabular}

The result show that there is medium relationship between the dependent variable and dependent variable. But the negative relationship between some of the variables like BLR has affected the economy in opposite direction. Although the SMEs credit to private sector has increased over the year negative relationship to the GDP implies that the private sector of Nepal isn't efficient. This means that SMEs aren't fulfilling the facility provided to the private sector. There is insignificant effect of banking system SMEs on economic growth.This shows that the financial institution are still in the development phase in both the country.

In the context of Nepal the bank lending rate has been fairly consistent over the years. This is the result of the lack of development activities in Nepal.The ratio of SME credit has negative effect on the economic growth. It means that though the RGDP and economic activities are increasing over the year, the proportion of SME loan has been 
declining. The major reasons adduced for the poor level of credit allocation to SMEs apart from government policy include lack of collateral securities, high interest rates, exchange rate fluctuations, high cost of processing small loans, delays in disbursement of fund, high risks of default associated with the SMEs sector.Despite the ever increasing economic growth, the proportion credit allocated to the SMEs has remained more or less constant. But the rapid economic growth requires the investment in industrial sector. The constant ratio SMEs credit implies that industrial sector hasn't expanded due to lack of investment and other private sector such as real estate and automotive sector are getting priority from the commercial bank for lending.

This study reveals that the allocation of total credit to SMEs rose significantly over the years from 2000 to 2015 . But the bank lending rate has variation due to poor economic situation of the country due to armed conflict and global economic crises. The favorable lending rate have helped the entrepreneurs to access the loan because of the lower cost of capital.

Given the global recognition of the role of SMEs in industrial and economic development of nation, there is no significant relationship with economic growth. The economic growth aren't the result of industrial development. The low economic growth over the past few years is the result of the agricultural sector growth, remittance income from abroad. The inability of banks to provide the required credit to SMEs, leads the entrepreneurs to rely on the personal saving for working capital needs thus making it difficult to operate at full capacity and increase in sales and output (Uremadu et al, 2014). The result reveals that the excessive protection policy from the bank for SMEs lending has affected the growth and development of the SMEs in Nepal.

\section{CONCLUSION}

This study investigated the impact of commercial bank credit to small and medium scale enterprises on economic growth of Nepal using unit root, co-integration analysis and OLS regression. There is the long term relationship between RGDP and SME loan.The percentage of credit facility provided to the SMEs in comparison to other private sector should be increased. The data analysis revealed that only 10-12 percent of the total loan to private sector is allocated to SMEs which is insignificant in terms of its impact on economic growth and employment. The existing bank lending rate is favorable in comparison with other county where lending rate to SMEs is as high as $25 \%$. Therefore, there should be focus to remain the bank lending rate low in Nepal. In this way only Nepal can achieve the economic progress in sustainable way. This will promote entrepreneurial environment and encourage those will lack to start the business and who have the difficulty to manage the business. 


\section{References}

Aurang, Z. (2012). Contributions of banking sector in economic growth: A case of Pakistan. Economics and Finance Review, 2(6), 45 - 54.

Dickey, D. A., \& Fuller, W. A. (1981). Likelihood ratio statistics for autoregressive time series with a unit root. Econometrica, 49, 1057-1072.

Johansen, S. (1991).Estimation and hypothesis testing of cointegration vectors in Gaussian vector autoregressive models. Econometrica, 59, 1551-1580.

Khatri, S.B., Aryal, R., \& Sapkota, N. (2008).Financial institution and economic growth: The case of Nepal.(Master's Degree Project in Finance).Retrieved from Finance http://his.diva-portal.org/smash/get/diva2:225151/FULLTEXT01.pdf

Nepal Rastra Bank. (2009).Financial sector development and economic growth in Nepal: FY 1975- FY 2007. Nepalese financial system: Growth and challenges. Kathmandu: Author.

Ochido, P. (2016). Relationship between credit accessibility and growth of small and medium size enterprises in Nairobi country Kenya. Kenya: University of Nairobi.

Philip, P.C.B., \& Perron, P. (1988).Testing for a unit root in time series regression. Biometrika, 75,335-346.

Uremadu, O., Ogechi, I., \& Okwuchukwu, O. (2014). Banking system credit to small and medium scale enterprises (SMEs) and economic growth in Nigeria: A cointegration approach. Journal of Economics and Finance, 41-51.

Zhang, J., Wang, L., \& Wang, S. (2012).Financial development and economic growth: Evidence from China. Retrieved from http://www.bm.ust.hk/ sswang/ homepage/Finance\%20and\%20Growth\%202012-01.pdf 
Appendix: Basic Data

\begin{tabular}{lcccc}
\hline $\mathbf{Y}$ & RGDP (Rs) & BCrTSMEs (Rs) & RBCrTSMEs ( ratio) & BLR (\%) \\
\hline 2000 & 292628 & 1522.464 & 1.650514192 & 13.25 \\
2001 & 290922 & 1787.73 & 1.715518673 & 12.0625 \\
2002 & 300914 & 1813.52 & 1.582061272 & 11.75 \\
2003 & 312267 & 2590.8 & 2.15289296 & 11 \\
2004 & 320729 & 3108.358 & 2.278796365 & 11.1875 \\
2005 & 326743 & 2953.4 & 1.878766327 & 10.91 \\
2006 & 531682 & 3150.3 & 1.789304725 & 10.75 \\
2007 & 560124 & 3261.6 & 1.492055955 & 10.75 \\
2008 & 590107 & 3469.6 & 1.343521004 & 10.25 \\
2009 & 618529 & 4044.66 & 1.043669298 & 10.375 \\
2010 & 639694 & 4812.8 & 1.062313348 & 10.96 \\
2011 & 670729 & 1387.84 & 0.275726478 & 11.75 \\
2012 & 697954 & 8411.76 & 1.457558067 & 12.4 \\
2013 & 739754 & 9388.74 & 1.354102681 & 12.09 \\
2014 & 759915 & 2216.72 & 0.259208441 & 10.55 \\
2015 & 764175 & 36687.31 & 3.787909622 & 8.86 \\
\hline
\end{tabular}

Source: NRB, Bank Supervision Report 2000-2015 